ISSN 1518-3483

Licenciado sob uma Licença Creative Commons

\title{
O Curso de Pedagogia: permanências e novas tensões
}

\section{The Pedagogy Course: permanences and new tensions}

\section{El curso de Pedagogía: permanencias y nuevas tensiones}

\author{
Elisângela Lisboa Micheletti, Cláudia Valentina A. Galian*
}

Universidade de São Paulo (USP) São Paulo, São Paulo, Brasil

\section{Resumo}

Este artigo trata da formação dos pedagogos no Brasil, cujas bases estão parcialmente definidas na implementação de Diretrizes Curriculares Nacionais para o curso. Buscamos identificar as mudanças na formação inicial e na percepção dos pedagogos quanto às contribuições da formação inicial para a sua atuação profissional, fomentadas em alguma medida pelas Diretrizes Curriculares Nacionais para o curso de Pedagogia (DCNP). A pesquisa, de natureza qualitativa, envolveu os seguintes procedimentos: análise documental, questionários e entrevistas desenvolvidos junto a dois grupos de pedagogos, formados e concluintes do curso nos períodos anterior e posterior à promulgação dos referidos documentos legais, de uma Universidade da cidade de São Paulo. Evidenciou-se uma série de mudanças significativas na composição do currículo, influenciadas essencialmente pelas demandas do trabalho docente, que conferiram 
ao currículo do curso uma base docente, especialmente em função de necessidades materiais impostas pelo contexto histórico e social. As mudanças evidenciadas alteraram a natureza e a organização do curso e esta foi a principal mudança ao longo da história desse curso, na busca por romper, de uma maneira peculiar, com a dualidade entre o bacharelado e a licenciatura. Como consequência, evidenciaram-se também alterações na sua organização, o que se deu por meio de um processo de redução do tempo de formação, sustentado por um "enxugamento" do currículo. Por fim, identificou-se uma mudança na percepção dos pedagogos quanto às contribuições da formação inicial para sua atuação profissional, essencialmente coerentes com a guinada do curso em direção ao preparo para as atividades docentes no âmbito escolar.

Palavras-chave: Formação Inicial de Professores. Currículo do curso de Pedagogia. Identidade profissional dos pedagogos.

\section{Abstract}

This article focuses on the training of pedagogues in Brazil, partially expressed in the implementation of national curriculum guidelines. We aimed to identify the changes that stand out in the initial formal training and the perception of pedagogues concerning what said initial training adds to their professional performance, to a certain extent fomented by the National Curriculum Guidelines for the Pedagogy course, which has restructured the course. The qualitative research comprehended documentary analysis, questionnaires and interviews with two groups of graduated and graduating pedagogues from a University located in São Paulo, Brazil, before and after the aforementioned legal documents were enacted. A series of significant changes about what constitutes the curriculum stood out and were essentially influenced by the demands of the work of educators, which granted the course curriculum a teaching base, particularly as a result of the material needs imposed by the historical and social context. The highlighted changes were those directly altering the Pedagogy course's nature and organization in such a way that it was the main change occurring throughout the curriculum history in Brazil, since it aimed to end the duality between a Bachelor's degree and a Teaching degree, within the plan of formative intents. Because of that, another significant change stood out concerning the course organization, which occurred by means of a process of reducing the time needed for 
graduating, supported by "streamlining" the curriculum. Finally, we identified a change in the pedagogues' perception of what the initial teacher training adds to their professional performance, which is essentially oriented toward teaching activities within the school environment.

Keywords: Initial Teacher Training. Curriculum of the Pedagogy course. Professional identity of the pedagogues.

\section{Resumen}

Este artículo trata de la formación de los pedagogos en Brasil, cuyas bases están parcialmente definidas en la implementación de las directrices curriculares nacionales para el curso. Buscamos identificar los cambios en la formación inicial y en la percepción de los pedagogos en lo referente a las contribuciones de la formación inicial para su actuación profesional, fomentadas en alguna medida por las Directrices Curriculares Nacionales para el curso de Pedagogía (DCNP). La investigación, cualitativa, abarcó los siguientes procedimientos: análisis documental, cuestionarios y entrevistas con los grupos de pedagogos formados y seniors del curso en los períodos anterior y posterior a la promulgación de los mencionados documentos legales, de una universidad de la ciudad de San Pablo. Se evidenciaron una serie de cambios significativos en la composición del currículo, influenciados principalmente por las demandas del trabajo docente, que confirieron al currículo del curso una base docente, especialmente en función de necesidades materiales impuestas por el contexto histórico y social. Los cambios evidenciados modificaron el carácter y organización del curso y éste fue el principal cambio a lo largo de la historia de ese curso, pretendiendo romper de una manera peculiar con la dualidad entre bachillerato y la licenciatura. Como consecuencia, se hicieron evidentes además cambios en su organización, lo que se dio por medio de un proceso de reducción del tiempo de formación, apoyado en un "achicamiento" del currículo. Finalmente, se identificó un cambio en la percepción de los pedagogos en relación a las contribuciones de la formación inicial para su actuación profesional, esencialmente coherentes con el viraje del curso orientado para la preparación para las actividades docentes en el ámbito escolar.

Palavras clave: Formación inicial. Currículum del Curso de Pedagogía. Identidad profesional de los pedagogos. 


\section{Introdução}

Este artigo focaliza as mudanças no curso de Pedagogia e na perspectiva dos pedagogos sobre as contribuições da formação inicial para sua atuação profissional, a fim de identificar como esses aspectos se relacionam, em alguma medida, com as determinações curriculares de produção central, tais como as Diretrizes Curriculares para o curso de Pedagogia (DCNP).

Sob a influência das concepções mercadológicas na educação, reflexo das políticas neoliberais que potencializaram o processo de privatização no Ensino Superior, como destacam Catani, Oliveira e Michelotto (2010, p. 269278), as DCNP delineiam um curso de formação que aponta para o alargamento do campo de atuação do pedagogo. Assume-se nesse documento que esse profissional terá, quando completado o curso, condições para atuar na pesquisa, na gestão escolar, em espaços de educação não escolar e na docência.

Este alargamento da função docente, combinado com uma redução ou um enfraquecimento das discussões teóricas no curso, como ressaltam Pimenta (2011) e Ricardo (2010), tem precarizado a formação do professor e consequentemente provocado sua desvalorização profissional, num movimento que tem como uma das possíveis consequências o rebaixamento salarial. Assim, partindo das inquietações em torno desse modelo de formação inicial dos pedagogos, desenvolveu-se a investigação ora apresentada. Em levantamento da produção acadêmica no período de 1996 a 2014, destacaram-se diversas posições em torno não só da identidade do pedagogo, mas da natureza do curso de Pedagogia. São exemplos dessas posições: que o pedagogo deve ser uma liderança no ensino e na pesquisa educacional (CARVALHO, 1996a); que o objeto central da atuação do pedagogo é o ensino, como ação intencional e planejada, o que atribui o seu caráter profissional, diferenciando-o de outros agentes que lidam com a educação na sociedade (CARVALHO, 1996b); que a Pedagogia deve ser tomada como Ciência da Educação e o pedagogo, como um agente da "ação educativa", que desenvolve a ciência prática da e para a Educação (PINTO, 2006); que a Pedagogia, como licenciatura, é necessária para formar os pedagogos escolares, que atuam dentro e fora da sala de aula, em ambiente escolar (PINTO, 2006); que a formação 
estritamente voltada para o magistério da Educação Infantil e anos iniciais do Ensino Fundamental não contempla as necessidades formativas dos educadores que vão atuar em espaços não escolares (PINTO, 2006; BIZARRO, 2009; 2012); que as adequações indicadas nos textos legais apontam para um novo conceito de docência, que visa abarcar todos os campos de atuação pedagógica (CAMPOS, 2009); que a identidade profissional do pedagogo é predominantemente uma identidade docente, que começa a ser construída no processo de formação e se consolida durante o exercício profissional (LUZ, 2010); que os estágios supervisionados devem incidir sobre os diversos campos de atuação do pedagogo (BIZARRO, 2012); que o curso deve responder às necessidades da formação para a gestão educacional, o que implica alterar o currículo, por meio da integração do curso e da redefinição de uma licenciatura que contemple, ao mesmo tempo, aspectos de bacharelado, ou seja, uma formação que vá além da docência (FRANCO, 2014).

Como fica claro a partir desses destaques, delinear a identidade profissional do pedagogo e do curso, não constitui uma tarefa fácil, já que uma série de divergências se apresentam, algumas muito antigas e outras que emergiram mais recentemente. Assim, vale destacar inicialmente alguns aspectos centrais do debate em torno do curso de Pedagogia, a partir da formulação das DCNP. Em seguida, no item Metodologia, delineiam-se as opções metodológicas utilizadas no desenvolvimento da pesquisa, seguidas dos resultados e, por fim, nas Conclusões, são desenvolvidas as análises a partir dos dados.

\section{O curso de Pedagogia: debates em torno da formulação das DCNP}

No panorama histórico apresentado por Brzezinski (1996), nota-se que o contexto social e econômico é determinante na identidade assumida para os cursos superiores. No caso da Pedagogia, o processo de democratização do ensino básico, a partir da década de 1980, que levou à universalização quase completa do Ensino Fundamental, é elemento determinante para impor ao curso uma base docente, no mesmo patamar das demais licenciaturas. 
Isto foi atrelado à exigência de formação em nível superior para os professores de Educação Infantil e anos iniciais do Ensino Fundamental, que demandou um grande número de professores com formação nesse nível. Ao longo da história do curso de Pedagogia no Brasil, a discussão em torno da questão da identidade deste profissional sempre esteve marcada por uma sucessão de ambiguidades, envolvendo essencialmente as disputas entre o bacharelado e a licenciatura. No entanto, é a partir da LDB 9394/96, e especialmente nos debates em torno da formulação de diretrizes curriculares nacionais para o curso, que essas divergências ganham destaque, quando se busca uma definição quanto à identidade do curso e do profissional a ser formado. É nesse sentido que focalizamos a seguir um pouco desses debates.

É importante ressaltar que, concomitantemente à tentativa de construção de diretrizes para o curso de Pedagogia, a LDBEN 9394/96 também orienta a criação do Curso Normal Superior, que passa a ser ministrado nos Institutos Superiores de Educação (ISE) e nas faculdades isoladas para formação de professores de Educação Infantil e anos iniciais do Ensino Fundamental, a fim de atender à exigência da formação docente em nível superior.

Sobre essa questão, merece destaque o insucesso do Conselho Nacional de Educação (CNE) em sua tentativa de reduzir o curso de Pedagogia à formação de especialistas e de transformar o Curso Normal Superior em espaço exclusivo de formação de professores para Educação Infantil e anos iniciais do Ensino Fundamental. Isto fez com que a proposta para o documento das DCNP - elaborada pela Comissão de Especialistas de Pedagogia e encaminhada à Secretaria de Educação Superior do Ministério da Educação (SESu/MEC) em maio de 1999 - desencadeasse, segundo Aguiar et al. (2006), um amplo processo de discussão, em nível nacional. Foram ouvidas as coordenações de cursos e diversas entidades da área. Mas, mesmo diante de grande pressão desses segmentos, o MEC resistia a encaminhá-lo ao CNE, na tentativa de construir diretrizes para o Curso Normal Superior. Diante das pressões e resistências, o documento foi encaminhado ao $\mathrm{CNE}$, onde permaneceu por quase oito anos, "aguardando a definição e regulamentação de outros pontos ainda polêmicos com relação à 
formação, como o próprio Curso Normal Superior, que até o momento não possuía suas próprias diretrizes" (AGUIAR et al., 2006, p. 825).

Após a aprovação das Diretrizes para Formação de Professores, em 2002, o CNE compôs uma Comissão Bicameral para definir as Diretrizes para o curso de Pedagogia e, em 2005, foi divulgado o Projeto de Minuta. A partir de então, o debate se intensificou ainda mais, se estendendo por todo país, com diferentes argumentos contrários a uma redução do curso ao seu caráter de licenciatura.

Dessa forma, o ano de 2005 foi marcado por grande disputa entre as forças intelectuais da área, acompanhada da divulgação de diversos Pareceres pelo CNE, que, aos poucos, foi incorporando as reivindicações e pressões feitas pelas diversas entidades. Entretanto, as discussões realizadas nos encontros e fóruns nacionais neste período denunciavam outro problema, que era a participação restrita e privilegiada de alguns grupos ligados ao CNE/MEC na construção das DCNP. Neste palco, dentre os grupos cujas vozes tinham menos impacto na constituição das DCNP estavam o Movimento Estudantil de Pedagogia (MEPe), organizado por entidades representativas, tais como a Executiva Nacional dos Estudantes de Pedagogia (ExNEPe) e as executivas estaduais e distrital, praticamente excluídas do processo, bem como os assinantes do Manifesto dos Educadores Brasileiros.

O MEPe encampou uma luta intensa em 2005 contra os Pareceres do CNE/MEC, bem como pela defesa da participação de todos os envolvidos nesse processo. Os estudantes chegaram a protocolar um documento no $\mathrm{MEC}$, nesse mesmo ano, que versava sobre a concepção de pedagogo que defendiam, mas, mesmo sendo assinado pelo Ministro, este documento foi ignorado com a homologação das DCNP, em maio de 2006. Após isso, o MEPe, por meio de suas entidades representativas nas diversas IES públicas e privadas de todo o país, aprovou, durante o XXVI Encontro Nacional de Estudantes de Pedagogia (ENEPe), realizado na Universidade Federal do Amapá, em junho de 2006, a luta pela Revogação das DCNP. O movimento pela revogação era uma exigência não apenas pela democratização do processo de discussão do documento. Tratava-se também da defesa de uma concepção de "pedagogo unitário", reivindicada com base nos princípios da escola unitária de Gramsci 
e na ideia de indissociabilidade entre a docência, a pesquisa e a gestão, que vinha sendo construída nos encontros estudantis. Esse movimento resistiu por um curto período, perdendo força com o processo de implementação das DCNP nas instituições em todo o país, bem como diante de outros fatores que marcaram o processo. Já o Manifesto dos Educadores Brasileiros expressava a posição de pelo menos 150 desses profissionais, liderado por educadores renomados, como José Carlos Libâneo e Selma Garrido Pimenta, dentre outros. Ele também constituiu posição contrária ao Parecer e à Resolução homologados pelo CNE/MEC. Este grupo compreendia o curso de Pedagogia como campo científico e investigativo, constituindo-se prioritariamente como uma ciência e, somente por isso, como um curso (MANIFESTO..., 2005, p. 1). Por esse motivo, esse grupo entendia que a especificidade do curso compreendia "a análise crítica e contextualizada da educação e do ensino enquanto práxis social [...], com vistas ao aprofundamento na teoria pedagógica, na pesquisa educacional e no exercício de atividades pedagógicas em diversos campos da sociedade" (MANIFESTO..., 2005, p. 2). Nesse sentido, durante o III Fórum Nacional de Pedagogia (FONAPE), realizado em Águas de Lindóia-SP, em novembro de 2006, foi aprovada a Carta de Lindóia, documento que, dentre outras propostas, sugeria que o curso se voltasse para "propiciar aprofundamento de estudos teóricos em Pedagogia e oferecer formação pedagógica aos licenciados que desejarem assumir funções não docentes no sistema de ensino, nas escolas e em espaços não-escolares", enquanto que nas diretrizes para a Licenciatura em Pedagogia a docência figurasse "como base da identidade profissional desse pedagogo" (FONAPE, 2006, p. 4)

Essas defesas levaram Libâneo (2006, p. 221), dentre outros assinantes do Manifesto dos Educadores Brasileiros, a recusar inteiramente os termos da Resolução do CNE. O autor entendia que, "por razões lógico-conceituais, o curso de Pedagogia pode incluir, mas não reduzir-se a um curso de formação de professores". E acrescentava que:

Não tem sustentação teórica afirmar que a base da formação do pedagogo é a docência. [...] Resulta em empobrecimento do campo científico e profissional da Pedagogia, atribuir a denominação pedagogo 
apenas aos professores que exercem o magistério na Educação Infantil e nos Anos Iniciais do ensino fundamental (Grifo do autor).

Em síntese, os autores acima citados, dentre outros signatários do Manifesto, defendem a Pedagogia como campo científico da Educação, que deve ter em sua formação a licenciatura e o bacharelado, dando ênfase ao bacharelado, que melhor ofereceria a formação científica, bem como a possibilidade de uma atuação mais ampla.

Outras entidades e grupos de intelectuais da educação se manifestaram, tendo grande parte deles se posicionado de forma contrária ao Parecer e à Resolução homologados pelo CNE/MEC. Como principais defensores das DCNP junto à Associação Nacional pela formação dos Profissionais da Educação (ANFOPE), estavam a Associação Nacional de Pós-Graduação e Pesquisa em Educação (ANPEd), a Associação Nacional de Política e Administração da Educação (ANPAE), o Centro de Estudos Educação e Sociedade (CEDES) e o Fórum Nacional de Diretores de Faculdades e os Centros de Educação das Universidades Públicas (FORUMDIR), que a consideravam "um avanço histórico no campo da formação dos profissionais da educação" (ANPEd, 2006, p. 1).Segundo Evangelista (2005), o CNE assumia que o pedagogo é um licenciado apto a atuar tanto na docência quanto nas funções de administração do sistema escolar, ou seja, capaz de realizar o trabalho pedagógico em sentido amplo. Conquanto sua formação fosse para a docência - dado que se formará numa licenciatura - o pedagogo não é apenas docente, razão pela qual é também designado, pelo CNE, de "educador". Seu espaço de atuação abrange instituições escolares e não escolares, bem como a produção e difusão do conhecimento científico e tecnológico. Explicita-se aqui sua dupla configuração: a Pedagogia é campo de estudos e campo de formação profissional. Em linhas gerais, foi neste contexto que se deu a formulação, bem como se iniciou o processo de implementação das DCNP pelo $\mathrm{CNE} / \mathrm{MEC}$, refletindo as disputas históricas em torno da identidade do pedagogo e do curso de Pedagogia. A partir daí um novo processo de discussão se iniciou nas IES, a partir da "aceitação" das DCNP. Assim, 
assumir o objetivo definido para a pesquisa de que trata este artigo implicou identificar os possíveis impactos que o Parecer CNE/CP n ${ }^{\circ} 3 / 2006$ e a Resolução CNE/CP n ${ }^{0}$ 1/2006 trouxeram para a formação inicial dos pedagogos, bem como as concepções de pedagogo aí implícitas.

\section{Metodologia}

No desenvolvimento da pesquisa optou-se por desenvolver um estudo qualitativo, que lançou mão dos seguintes procedimentos: análise documental, questionários e entrevistas. As fontes foram os documentos federais que definem as bases para o funcionamento do curso de Pedagogia — os Pareceres CNE/CP nº 9/2001 e n 27/2001 e a Resolução CNE/CP nº 1/2002; o Parecer CNE/CP n ${ }^{\circ} 3 / 2006$ e a Resolução CNE/CP n 1/2006 -, os documentos curriculares de um curso de Pedagogia e as declarações de pedagogos formados no período anterior e de concluintes do curso, em fase posterior à promulgação das DCNP. Trabalhou-se com um grupo de 13 egressos que se formaram em 2007, no curso organizado segundo a última configuração de matriz curricular dividida em habilitações (denominado de Grupo A), e outro grupo de 19 estudantes/concluintes que estavam cursando em 2015 o último semestre do curso, já organizado de acordo com as DCNP (Grupo B).

A Universidade é privada, de caráter confessional, instalada na cidade de São Paulo. Nela, o curso de Pedagogia é ofertado desde 1972, a princípio apenas com a Habilitação em Administração Escolar, tendo sido agregadas, em 1979, a Habilitação em Magistério de Deficientes Mentais e Orientação Educacional e, em 2000, a Habilitação para o Magistério na Educação Infantil e Magistério para $1^{\mathrm{a}}$ a $4^{\mathrm{a}}$ séries do Ensino Fundamental. Atualmente, após aproximadamente 45 anos, o Projeto Pedagógico Curricular (PPC) de 2014 traz a afirmação da formação de profissionais para a docência na Educação Infantil e anos iniciais do Ensino Fundamental e para a Gestão e Coordenação do Trabalho Pedagógico em espaços escolares e não escolares, em um curso presencial com duração de sete semestres. Essa escolha se justifica pela preocupação 
com a representatividade da situação analisada, uma vez que nos últimos anos os cursos de licenciatura têm crescido majoritariamente nesse setor (GATTI; BARRETTO; ANDRÉ, 2011, p. 102). Mas, vale destacar que esse curso de Pedagogia conta com uma tradição sólida e uma estrutura privilegiada; assim, por ser uma instituição privada, ela em certa medida está submetida às pressões mercadológicas no campo da Educação, mas conta também com o reconhecimento da qualidade do curso.

Para a abordagem das DCNP, três questões orientaram a análise documental: como elas concebem o profissional pedagogo; qual é a concepção de docência implícita nesse documento; e como ele orienta a organização do curso de Pedagogia em relação aos aspectos ligados à formação do professor e à formação para atuação em outros âmbitos educacionais. Para trabalhar com os documentos curriculares da Universidade - o primeiro, correspondente ao período de 2003-2007 e o segundo, correspondente ao período atual —, lidou-se com uma questão de investigação: que diferenças podem ser verificadas, quanto à natureza e à organização do curso de Pedagogia, quando se comparam os currículos concebidos em período anterior e posterior às DCNP.

No caso dos questionários, foi central a questão: qual a concepção que os egressos, formados em período anterior, e os concluintes, em etapa posterior às DCNP, expressam sobre as contribuições da formação inicial para sua atuação e como avaliam sua formação inicial em relação a essa concepção. As entrevistas foram organizadas a partir das lacunas encontradas no questionário, principalmente nas questões abertas, que não foram respondidas ou o foram de forma muito breve. Assim, a ideia foi buscar nas entrevistas as justificativas das escolhas quanto aos saberes que os sujeitos julgavam necessários e imprescindíveis na formação dos pedagogos e suas concepções sobre o papel dos estágios na formação inicial.

\section{O que evidenciam os documentos}

Evidenciou-se a ausência de especificações mais claras nas DCNP em relação à identidade profissional do pedagogo, prevalecendo apenas a 
docência como elemento definidor dessa identidade. Neste sentido, foi preciso buscar entender o conceito de docência para compreender o que se define como identidade profissional do pedagogo nesse documento. Ela é compreendida como ação que vai além da atividade desenvolvida pelo professor em sala de aula, ou seja, prevê a participação na organização e gestão de sistemas e instituições de ensino e na produção e difusão do conhecimento científico e tecnológico do campo educacional, em contextos escolares e não escolares. Pode-se dizer que as DCNP sugerem ao pedagogo uma identidade profissional que se reveste de uma base docente, a ser prioritária na formação, mas que supõe uma sobrecarga de funções no que se refere aos campos de atuação. Quando a análise focaliza os PPC do curso — de 2003 e de 2014 - fica bastante evidente a ampliação expressiva das disciplinas de formação docente no curso, em detrimento daquelas voltadas à formação para os demais campos de atuação. Após as DCNP, no PPC de 2014, se observa uma perda bastante significativa das disciplinas de Fundamentos da Educação, por meio de um corte de aproximadamente metade da carga horária, acompanhado de uma ampliação das disciplinas de Formação Docente, núcleo no qual já se tinham implantado 18 disciplinas em 2003 e que acaba incorporando mais 16 disciplinas após as DCNP, passando de $32 \%$ para $55,2 \%$ da carga horária total do curso. Quanto às questões relacionadas à gestão educacional, além da alteração na carga horária deste núcleo temático, as mudanças de conteúdo também foram expressivas, já que o conceito de gestão educacional na versão curricular posterior às DCNP compreende tanto a gestão escolar como a gestão educacional em âmbito não escolar, de forma integrada, como se não houvesse especificidades em cada um desses âmbitos. Apesar das mudanças assinaladas acima, essa Universidade buscou meios de preservar os aspectos da antiga Administração Escolar na formação dos pedagogos, tidas como conquistas do curso de Pedagogia nesta IES. O mesmo movimento de preservação das conquistas históricas do curso pode se verificar também no que se refere às questões relacionadas ao ensino das pessoas com deficiência, o que se evidencia na oferta atual de quatro disciplinas que têm como objetivo oferecer subsídios mínimos para o atendimento das pessoas com deficiência, sob a perspectiva da inclusão escolar. 
No que se refere ao desenvolvimento da pesquisa educacional no curso, não houve mudanças quanto aos objetivos assumidos para essa atividade; porém, com a extinção das disciplinas de Estudos Independentes, que perpassavam todos os semestres do curso, possivelmente as condições para o desenvolvimento da pesquisa foram modificadas, ficando restritas ao desenvolvimento do TCC, no final do curso.

Em relação aos estágios supervisionados, nos dois documentos curriculares é definida uma perspectiva interdisciplinar para a sua abordagem e sua realização se dá desde os primeiros semestres do curso. Todavia, essa atividade sofreu mudanças expressivas em sua organização - dentre elas a redução da carga horária, que era de 580 horas para os que cursavam a habilitação em Deficiência Mental e de 490 horas para os que cursavam a habilitação de Gestão Escolar. Na versão atual, passou-se a exigir o cumprimento de apenas 340 horas. Deixou-se de contar com os subsídios dos Estudos Independentes e passou-se a contar apenas com atividades de observação da docência. Na versão curricular anterior às DCNP, além da observação da docência havia a possibilidade de realizar os estágios por meio de participação em projetos e da regência. Como parte dos estágios estava ligada às habilitações, também era prevista sua realização para além da sala de aula.

Portanto, a análise dos documentos curriculares evidenciou uma série de mudanças quanto à natureza e à organização do curso de Pedagogia, principalmente a partir das medidas que reestruturaram o curso em 2006, mas que já vinham sendo fomentadas em função das disputas em torno da identidade do curso, o que sinaliza para possíveis mudanças na atuação profissional dos pedagogos.

\section{O que destacam os sujeitos da pesquisa}

Num esforço por sintetizar os apontamentos feitos pelos sujeitos da pesquisa, verificou-se que os que concluíram o curso em 2003 o caracterizam como "muito teórico", o que pode se explicar diante da carga horária significativa de disciplinas de fundamentação teórica que compunha a 
matriz curricular. Já os concluintes de 2015 apontam apenas a necessidade de melhorar a relação entre a teoria e a prática, pois consideram que, em relação a grande parte dos conteúdos que estudaram, não sabem como "aplicar” esse conhecimento. Tal observação pode estar relacionada não apenas à pequena carga horária destinada à fundamentação teórica na matriz curricular mais recente, mas ao desequilíbrio na distribuição das disciplinas ao longo dos semestres, bem como à forma de organização dos estágios.

As declarações evidenciam que os egressos sinalizam as contribuições dos estágios nos campos da docência e da gestão e o grupo de concluintes aponta apenas a docência. No que se refere aos saberes articulados no curso, egressos e concluintes revelam uma mesma lacuna central: trata-se da formação para lidar com a diversidade e a pluralidade cultural. Identificase uma contradição no que se refere à concepção de pedagogo dos sujeitos em relação aos campos de atuação profissional que se vislumbra nos documentos curriculares. Por um lado, quando olhamos para a concepção contida nas DCNP e nos documentos curriculares, é evidente um movimento de suposta ampliação dos campos de atuação - que abrangem o âmbito escolar e não escolar —, que consequentemente demanda uma formação também ampliada, menos fragmentada, que possibilite uma base formativa comum a todos os profissionais da Educação, para que sejam capazes de atuar em diferentes contextos educacionais. No entanto, as declarações dos egressos e as mudanças na composição curricular demonstram o contrário, ou seja, que a atuação e a formação têm se voltado fundamentalmente para a docência nos anos iniciais da educação básica. Isso sugere, mesmo que de forma indireta, a necessidade de uma formação complementar para a ação nos demais campos de atuação do pedagogo.

\section{Considerações finais}

Ainda que se trate de um estudo de caso, acredita-se que as conclusões deste estudo podem representar possíveis tendências no processo de reformulação do curso de Pedagogia no Brasil. Assim, inicialmente, com base na 
concepção marxista, acreditávamos que a reestruturação do curso expressava as pressões impostas pelas reformas educacionais de cunho neoliberal, que impuseram algumas consequências ao Ensino Superior. Isso teria acarretado acima de tudo a desvalorização profissional (ou o rebaixamento da força de trabalho), em função principalmente da redução do tempo exigido para a formação em concomitância com uma suposta ampliação dos campos de atuação.

Encontra-se sustentação para essa ideia nas contribuições de Catani, Oliveira e Michelotto (2010) e Gatti, Barretto e André (2011), que demonstram o aligeiramento da formação inicial docente em meio a um contexto de privatização do Ensino Superior, sob o signo da redução de investimentos públicos, bem como com a criação de novos mercados na educação, por meio da transferência de parte da formação para os cursos de pós-graduação. A principal consequência desse processo relaciona-se aos dados apresentados por Gatti, Barreto e André (2011), com base no censo escolar de 2009, que mostram uma diminuição significativa da procura pelos cursos de licenciatura, principalmente no que se refere às matrículas nos cursos presenciais, além de uma evasão de $30 \%$. Outro aspecto que inicialmente chamava atenção era a constatação de que a identidade do pedagogo havia se voltado, com a aprovação das DCNP, fundamentalmente à formação para o trabalho docente. Além de evidenciarmos isso na produção acadêmica, pudemos confirmar essa ideia a partir dos elementos centrais da história do curso de Pedagogia no Brasil, da análise dos documentos legais e dos documentos curriculares, bem como dos depoimentos dos pedagogos. No entanto, vale ressaltar que o fortalecimento da base docente já vinha sendo construído na prática antes da aprovação das DCNP, primeiramente por meio do Parecer $n^{\circ} 161 / 1986$, que facultava ao curso a oferta da formação para a docência na Educação Infantil e anos iniciais do Ensino Fundamental, por meio de habilitações específicas, além da exigência posterior, colocada pela LDB 9394/96, de formação dos professores dos anos iniciais da educação básica em nível superior, que se deu por meio da extinção gradativa dos cursos de magistério (nível médio) e da aprovação de DCN para os cursos de licenciatura, em 2002. Isto, na instituição focalizada, 
resultou em uma primeira reforma, anterior às DCNP, que já apontava para a centralidade da formação docente.

Esse processo confirma a concepção materialista da história, aqui defendida, já que, antes de uma alteração oficial no currículo prescrito do curso, já existia uma base material que sustentava essa reforma. Essa base material era justamente a necessidade de se formar um grande contingente de professores para a Educação Infantil e anos iniciais do Ensino Fundamental, demanda que foi ampliada com o processo de democratização do acesso à escola, bem como com a gradativa expansão do atendimento na Educação Infantil.

Sobretudo, considera-se que a principal contribuição da pesquisa é a percepção de que, com as DCNP, a dualidade bacharelado-licenciatura, ao menos no âmbito das intenções formativas, parece ter sido evitada com a ênfase sobre a base docente na configuração de um curso de licenciatura, embora ainda seja possível observar, principalmente nos documentos curriculares do curso, uma dispersão dos conhecimentos mobilizados com o intuito de conferir subsídios para uma atuação profissional mais abrangente, em diferentes contextos educacionais.

Vale mencionar ainda que as demais áreas de atuação do pedagogo também são sustentadas por essa base e são justificadas nas DCNP como forma de garantir uma gestão democrática nas instituições de ensino público. Isto representa uma expectativa descolada da realidade, pois as relações de trabalho são determinantes no processo social, político e intelectual da vida em sua totalidade. Assim, a formação por si só não é capaz de possibilitar uma gestão democrática nas escolas enquanto persistirem as relações hierárquicas e autoritárias no seu interior. Essa expectativa baseia-se numa perspectiva idealista que afirma que, por meio da formação, se pode transformar a consciência humana para, posteriormente, se transformar a realidade. $\mathrm{O}$ mais provável é que a formação, a serviço da ideologia dominante, possa representar um dos mecanismos de sustentação dessas divisões desde a formação, uma vez que o currículo, como afirma Gimeno Sacristán (2000) é objeto de regulações econômicas, políticas e administrativas e, por isso, não pode ser compreendido à margem do contexto em que se constitui. 
Um último aspecto merece atenção: acreditava-se que seria possível identificar um "enxugamento" do currículo do curso de Pedagogia, em função de uma conjuntura política e econômica que impunha uma determinada base comum de conhecimentos. Comprovamos essa ideia por meio da análise dos documentos curriculares do curso, na redução de 50\% da carga horária das disciplinas correspondentes aos Fundamentos da Educação. Identificou-se também a redução dos estágios supervisionados na docência e a extinção dos estágios em outros campos de atuação do pedagogo. Quanto à implantação de novas disciplinas, a maioria está voltada para a formação docente e poucas para os demais campos de atuação do pedagogo. Nesse sentido, a composição atual do curso de Pedagogia se volta fundamentalmente para os aspectos da prática docente, o que pode estar em acordo com a tendência apontada por Saviani (2005) e Duarte (2005), que reconhecem a influência das pedagogias do "aprender a aprender". Isso significaria considerar que o papel dos professores se limitaria ao estímulo dos alunos para a construção de conhecimentos a partir de seus próprios interesses ou necessidades, o que tornaria menos importante dominar outros conhecimentos. Por outro lado, a regulação cada vez maior do currículo prescrito e organizado na escola, por meio do controle da produção e da distribuição dos materiais didáticos, afirmaria a necessidade de um novo perfil docente, cuja formação visa uma atuação polivalente e menos específica (PIMENTA, 2011; RICARDO, 2010). Também Almeida (2008) e Dias (2011) mencionam essa polivalência. Ambos os estudos a caracterizam como uma exigência atual do mercado, indutora de uma formação por meio de habilidades e competências para uma atuação polivalente dos trabalhadores em geral. Inclusive, para dar maior sustentação aos interesses em torno da superexploração do trabalho polivalente, muitas vezes se utiliza de forma distorcida o discurso da gestão democrática, para legitimar essa nova exigência do mercado de trabalho.

Nesse sentido, identificou-se uma grande contradição na análise: o modelo anterior de formação, dividido em habilitações, possibilitou aos egressos a inserção em uma variedade maior de campos de atuação, enquanto que o grupo formado na matriz curricular atual, supostamente mais ampla, 
limitou tanto a expectativa de atuação quanto a atuação propriamente dita, quase que exclusivamente voltando-se para a docência. Sobretudo, reconheceu-se uma série de mudanças significativas no curso de Pedagogia, influenciadas essencialmente pelas demandas do trabalho docente. Os dados também permitiram compreender que o currículo regulamentado a partir das DCNP está em total acordo com a lógica econômica vigente; portanto, outros currículos certamente expressarão as marcas de novos embates em torno de necessidades e interesses presentes em outros contextos históricos e sociais.

\section{Referências}

AGUIAR, M. A. S. et al. Diretrizes Curriculares do curso de Pedagogia no Brasil: Disputas de Projetos no campo da Formação do Profissional da Educação. Educ. Soc., Campinas, v. 27, n. 96 (Especial), p. 819-842, out. 2006. Disponível em: <http://www.scielo.br/pdf/es/v27n96/a10v2796.pdf〉. Acesso em: 05 dez. 2017.

ALMEIDA, A. L. M. de. O pedagogo especialista em educação: origem e extinção na política educacional brasileira. 2008. 163 p. Dissertação (Mestrado) Universidade Federal do Sergipe, São Cristóvão, 2008.

ASSOCIAÇÃO NACIONAL DE PÓS-GRADUAÇÃO E PESQUISA EM EDUCAÇÃO (ANPEd). Pronunciamento conjunto das entidades da área da Educação: ANPEd, ANFOPE, ANPAE, FORUMDIR, CEDES. 2006. Disponível em: <http://www. anped.org.br/docs/pronunciamentoconjunto2006.doc>. Acesso em: 20 jan. 2007.

BRASIL. Ministério da Educação. Lei de Diretrizes e Bases da Educação Nacional n ${ }^{\circ}$ 9394/96 de 20 de dezembro de 1996. Diário Oficial da União. Brasília. Disponível em: <http://www.planalto.gov.br/ccivil_03/leis/19394.htm>. Acesso em: 04 jun. 2015.

BRASIL. Conselho Nacional de Educação. Parecer CNE/CP no 9/2001. Diretrizes Curriculares Nacionais para a Formação de Professores da Educação Básica, em nível superior, curso de licenciatura, de graduação plena. Diário Oficial da União. Brasília. Disponível em: 〈http://portal.mec.gov.br/cne/arquivos/pdf/009.pdf〉. Acesso em: 24 jan. 2017. 
BRASIL. Conselho Nacional de Educação. Parecer CNE/CP n 27/2001. Dá nova redação ao item 3.6, alínea c, do Parecer CNE/CP 9/2001, que dispõe sobre as Diretrizes Curriculares Nacionais para a Formação de Professores da Educação Básica, em nível superior, curso de licenciatura, de graduação plena. Diário Oficial da União. Brasília. Disponível em: <http://portal.mec.gov.br/cne/arquivos/ pdf/027.pdf >. Acesso em: 24 jan. 2017.

BRASIL. Conselho Nacional de Educação. Resolução CNE/CP n ${ }^{\circ}$, de 18 de fevereiro de 2002. Institui Diretrizes Curriculares Nacionais para a Formação de Professores da Educação Básica, em nível superior, curso de licenciatura, de graduação plena. Diário Oficial da União. Brasília, 2002.

BRASIL. Conselho Nacional de Educação. Conselho Pleno. Parecer CNE/CP n ${ }^{\circ}$ 3/2006. Institui Diretrizes Curriculares Nacionais para o curso de graduação em Pedagogia, homologado MEC em 21 de fevereiro de 2006. Brasília: CNE, 2006a.

BRASIL. Conselho Nacional de Educação. Conselho Pleno. Resolução CNE/CP n ${ }^{\circ}$ 1 de 15 de maio de 2006. Institui Diretrizes Curriculares Nacionais para o curso de graduação em Pedagogia. Diário Oficial da União. Brasília, 2006b.

BIZARRO, A. M. S. Currículo, Formação e Identidade do Pedagogo: Uma análise atual a partir do texto Formação do Educador - a busca da identidade do Curso de Pedagogia. In: COLÓQUIO INTERNACIONAL DE POLÍTICAS E PRÁTICAS CURRICULARES - DIFERENÇA NAS POLÍTICAS DE CURRÍCULO, 9., 2009, João Pessoa. Anais... João Pessoa, 2009. Disponível em: <http://www.geppc.org.br/sites/default/files/uploads/evento/191/anais/gt11.pdf〉. Acesso em: 16/07/2015.

BIZARRO, A. M. S. Formação do pedagogo: um olhar sobre a trajetória profissional dos/as egressos/as do Curso de Licenciatura em Pedagogia da UPE-Campus Garanhuns de 1996 a 2010. 2012. 199 p. Tese (Doutorado em Educação) Universidade do Estado do Rio de Janeiro, Rio de Janeiro, 2012.

BRZEZINSKI, I. Pedagogia, pedagogos e formação de professores: busca e movimento. Campinas: Papirus, 1996. (Coleção Magistério: Formação e Trabalho Pedagógico). 
CAMPOS, H. C. do N. A identidade profissional do pedagogo no curso de pedagogia da UFPA e nas diretrizes curriculares nacionais: aproximações e distanciamentos. 2009. 122 p. Dissertação (Mestrado) — Universidade Federal do Pará, Belém, 2009.

CATANI, A. M.; OliVEIRA, J. F. de; MICHELOTTO, R. M. As políticas de expansão da educação superior no Brasil e a produção do conhecimento. Série Estudos: Periódico do PPG Educação da UCD, Campo Grande, n. 30, p. 267-281, jul./dez. 2010.

CARVALHO, A. M. P. de. Identidade Profissional do Pedagogo: introduzindo o debate. In: Identidade do Pedagogo. Comissão de Publicações da FEUSP. São Paulo: FEUSP, 1996a. 85 p. (Estudos e documentos, v. 36).

CARVALHO, J. S. A identidade do Pedagogo: agente institucional do ensino. In: Identidade do Pedagogo/Comissão de Publicações da FEUSP. São Paulo: FEUSP, 1996b. 85 p. (Estudos e documentos, v. 36).

DIAS, I. S. O pedagogo nos espaços fora da escola. São Luís: EDUFMA, 2011. 150 p.

DUARTE, N. Porque é necessária uma análise crítica marxista do construtivismo? In: LOMBARDI, J. C.; SAVIANI, D. (orgs). Marxismo e Educação: debates contemporâneos. Campinas: Autores Associados: HISTEDBR, 2005.

EVANGELISTA, O. Curso de Pedagogia: projetos em disputa. Projeto PIBIC/CNPq 2005-2006. Florianópolis: EED/CED/UFSC, 2005.

FÓRUM NACIONAL DE PEDAGOGIA (FONAPE), 3., 2006, Águas de Lindóia. Carta de Lindóia. São Paulo, 2006.

FRANCO, A. de P. A formação dos gestores escolares nos cursos de Pedagogia. 2014. 321 p. Tese (Doutorado em Educação) — Universidade de São Paulo, São Paulo, 2014.

GATTI, B. A.; BARRETTO, E. S. de S.; ANDRÉ, M. E. D. de A. Políticas docentes no Brasil: um estado da arte. Brasília: UNESCO, 2011. 300 p.

GIMENO SACRISTÁN, J. O currículo: Uma reflexão sobre a prática. Porto Alegre: Artmed, 2000. 
LIBÂNEO, J. C. Diretrizes curriculares da Pedagogia: Um adeus à Pedagogia e aos pedagogos? In: SILVA, A. M. M.; MACHADO, L. B.; MELO, M. M. O.; AGUIAR, M. da C. C. (orgs.). ENCONTRO NACIONAL DE DIDÁTICA E PRÁTICA DE ENSINO. NOVAS SUBJETIVIDADES, CURRÍCULO, DOCÊNCIA E QUESTÕES PEDAGÓGICAS NA PERSPECTIVA DA INCLUSÃO SOCIAL, 1., Recife. Anais... Recife: ENDIPE, 2006. p. 213-276.

LUZ, T. H. B. e S. Ser pedagogo: o conhecimento da identidade profissional pelas histórias de vida. 2010. 166 p. Dissertação (Mestrado) — Universidade Federal do Piauí, Teresina, 2010.

MANIFESTO dos Educadores Brasileiros. São Paulo. 20 out. 2005. Mimeo.

PIMENTA, S. G. Pedagogia e pedagogos: caminhos e perspectivas. São Paulo: Cortez, 2011.

PINTO, U. de A. Pedagogia e Pedagogos escolares. 2006. 184 p. Tese (Doutorado) Faculdade de Educação, Universidade de São Paulo, São Paulo, 2006. Disponível em: <http://www.bdtd.ibict.br >. Acesso em: 20 ago. 2012.

RICARDO, E. C. Discussão acerca do ensino por competências: problemas e alternativas. Cadernos de Pesquisa, São Paulo, v. 40, n. 140, p. 605-628, maio/ago. 2010.

SAVIANI, D. Educação Socialista, Pedagogia Histórico-crítica e os desafios da sociedade de classes. In: LOMBARDI, J. C.; SAVIANI, D. (orgs). Marxismo e Educação: debates contemporâneos. Campinas: Autores Associados: HISTEDBR, 2005.

Recebido: 16/10/2017

Received: 10/16/2017

Recibido: 16/10/2017

Aprovado: 24/11/2017

Approved: $11 / 24 / 2017$

Aprobado: 24/11/2017 